\title{
IMOBILIZAÇÃO DA LIPASE DE Aspergillus japonicus EM ARGILA MONTMORILONITA KSF POR ADSORÇÃO FÍSICA: DETERMINAÇÃO DOS VALORES ÓTIMOS DE pH E TEMPERATURA
}

\author{
B. R. FERRARI ${ }^{1}$, A. J. SCHWANKE ${ }^{2}$, S. PERGHER ${ }^{2}$, V. C. S. EBINUMA ${ }^{1}$, A. V. \\ PAULA $^{1}$ \\ ${ }^{1}$ Universidade Estadual Paulista Júlio Mesquita Filho, UNESP, Faculdade de Ciências \\ ${ }^{2}$ Universidade Federal do Rio Grande do Norte, Centro de Ciências Exatas e da Terra \\ Farmacêuticas/Departamento de Bioprocessos e Biotecnologia - Rodovia Araraquara- \\ Jaú, CEP: 14800-903, Araraquara - SP - Brasil \\ e-mail: barbaraferrari30@gmail.com, ariela@fcfar.unesp.br.
}

\begin{abstract}
RESUMO - A aplicação de enzimas em diferentes sínteses, visando à obtenção de produtos com alto valor agregado, é um dos campos mais promissores dentro da tecnologia enzimática. Nesse sentido, a exploração de novas técnicas para produção de enzimas leva à manipulação de diferentes microrganismos. Dentre as enzimas disponíveis, as lipases são capazes de catalisar a hidrólise total ou parcial de triacilglicerídeos, atuando sobre as ligações ésteres presentes na molécula e promovendo a liberação de ácidos graxos e glicerol. Neste contexto, o objetivo do presente trabalho foi produzir, caracterizar e imobilizar lipases por cultivo submerso de cepas de Aspergillus japonicus DPUA1727. Após a produção da enzima obteve-se o filtrado enzimático, o qual foi liofilizado. O material liofilizado foi imobilizado por adsorção física em argila montmorilonita KSF e a enzima na forma livre e imobilizada foi caracterizada em relação ao $\mathrm{pH}$ e a temperatura ótima de atuação. Os resultados de $\mathrm{pH}$ ótimo e temperatura ótima foram os mesmos, 8,0 e $30^{\circ} \mathrm{C}$, respectivamente.
\end{abstract}

\section{INTRODUÇÃO}

Lipases (EC 3.1.1.3) são enzimas pertencentes ao grupo das hidrolases e denominadas glicerol ésteres hidrolases (HASAN, SHAH, HAMEED; 2009). A versatilidade das lipases permite que estas enzimas sejam selecionadas para aplicações potencias em diversos setores (alimentício, de detergentes, farmacêutico, têxtil, cosmético e indústrias de papel) (FERREIRA-DIAS et al., 2013; NUNES et al., 2011), constituindo assim um importante grupo de enzimas para aplicações biotecnológicas (HASAN; SHAH; HAMEED, 2006).

As lipases podem ser obtidas a partir de diferentes fontes, estas, podendo ser vegetais, animais e microrganismos. Do ponto de vista econômico e industrial, lipases de origem microbiana apresentam vantagens devido à facilidade de obtenção por processos fermentativos (PADILHA et al., 2011), bem como maior estabilidade 
(CONTESINI et al., 2010). Dentre os microrganismos produtores de lipases, os fungos filamentosos são amplamente conhecidos como fonte de lipases extracelulares. Dentre estes, cepas de Aspergillus são importantes microrganismos utilizados na área biotecnológica devido a sua capacidade de produzir enzimas extracelulares reconhecidas como GRAS (geralmente considerada como seguro) pelo FDA (MHETRAS, PATIL, GOKHALE; 2010).

O desenvolvimento de técnicas de imobilização tem sido fundamental uma vez que propiciam a reutilização das lipases, facilitam a separação dos produtos, aumentam a estabilidade em solventes orgânicos (GUISAN, 2006), além de conferir, por exemplo, maior estabilidade ao $\mathrm{pH}$ e à temperatura (ZANIN; MORAES, 2004). Desta forma, a imobilização torna o processo viável sob os pontos de vista comercial e econômico (D'AGOSTINI, 2001). Nesse contexto o objetivo deste trabalho foi produzir lipase de Aspergillus japonicus por cultivo submerso, imobilizar em montmorilonita KSF por adsorção fisica e caracterizar quanto aos valores ótimos de pH e temperatura.

\section{METODOLOGIA}

\subsection{Produção de Lipase por Cultivo Submerso de Aspergillus Japonicus}

Para a produção da lipase, o inóculo foi realizado em Placa de Petri contendo meio ágar batata dextrose (BDA). O crescimento do microrganismo ocorreu durante 7 dias a $30^{\circ} \mathrm{C}$. A seguir, 20 discos de micélio $(8 \mathrm{~mm}$ de diâmetro) retirados da margem da colônia com auxílio de tubos de ferro foram transferidos para frascos tipos Erlenmeyers $(500 \mathrm{~mL})$ contendo $100 \mathrm{~mL}$ do meio de cultivo com a seguinte composição $(\mathrm{g} / \mathrm{L})$ : peptona bacteriológica (40,0), azeite de oliva $(1,6) ; \mathrm{MgSO}_{4} .7 \mathrm{H}_{2} \mathrm{O}(1,2) ; \mathrm{KH}_{2} \mathrm{PO}_{4}(2,0)$; $\mathrm{NH}_{4} \mathrm{NO}_{3}(2,0) . \mathrm{O} \mathrm{pH}$ inicial foi ajustado para 7,0. O cultivo submerso foi conduzido em agitador orbital por 72 horas a $30^{\circ} \mathrm{C}$ e $150 \mathrm{rpm}$. Ao fim do cultivo, a biomassa foi separada por filtração em papel de filtro Whatman $\mathrm{n}^{\circ} 1$ e o filtrado contendo as lipases empregado no processo de imobilização e caracterização. Os cultivos foram feitos em triplicata.

\subsection{Determinação da atividade hidrolítica}

Para determinação dos da atividade hidrolítica empregou-se o método titulométrico utilizando-se como substrato emulsão de azeite de oliva (Paula, 2012).

\subsection{Imobilização por Adsorção Física em Meio Aquoso}

O procedimento de imobilização da lipase em meio aquoso foi estabelecido com base na metodologia proposta por Vescovi et al. (2016), com modificações. O suporte utilizado foi Argila Montmorilonita KSF. Para a imobilização, 1g de suporte foi mantido em suspensão com $25 \mathrm{~mL}$ de solução enzimática em tampão (fosfato $\mathrm{pH} 7,0$; $25 \mathrm{mM}$; contendo $20 \mathrm{mg} / \mathrm{mL}$ de proteína). A suspensão foi mantida na cama de rolo à temperatura ambiente, sob agitação, por $24 \mathrm{~h}$. Paralelamente, foi feito um controle, ao qual não se adicionou suporte. Após 24h, o derivado imobilizado foi centrifugado (5000 
rpm, 5 minutos). O sobrenadante foi coletado e o sólido foi transferido para placa de Petri, sendo mantido em geladeira por $24 \mathrm{~h}$. Foi quantificado o teor de proteínas (Bradford, 1976) do sobrenadante.

\subsection{Rendimento de imobilização}

O rendimento de imobilização das enzimas foi calculado utilizando-se as absorbância obtidas através da determinação de proteínas totais pelo método de Bradford, de acordo com a Equação 1:

$$
n(\%)=100-\left(\frac{A x 100}{A 0}\right)
$$

Em que: $\mathrm{A}=$ absorbância do sobrenadante do derivado imobilizado; Ao = absorbância do controle no tempo zero.

\subsection{Determinação de pH e Temperatura ótimos}

Para determinação dos valores de temperatura e $\mathrm{pH}$ ótimos da lipase de Aspergillus japonicus empregou-se o método titulométrico utilizando-se como substrato emulsão de azeite de oliva (Paula, 2012 modificado). O pH ótimo da enzima foi determinado pela quantificação da atividade da lipase a $25^{\circ} \mathrm{C}$ a diferentes níveis de $\mathrm{pH}$ $(3,0$ a 10,0). $\mathrm{O}$ pH no qual a enzima se manteve mais estável foi selecionado para o estudo de estabilidade e atividade ótima em relação a temperatura. A temperatura ótima da enzima foi determinada pela atividade enzimática a várias temperaturas ( 20 a $60^{\circ} \mathrm{C}$ ).

\section{RESULTADOS}

\subsection{Produção e imobilização da Lipase de Aspergillus japonicus}

Após a produção da lipase de A. japonicus, em meios de cultivo com azeite de oliva como substrato, foram quantificados biomassa $(\mathrm{g} / \mathrm{L})$, concentração proteica e atividade hidrolítica. Os resultados são apresentados na Tabela 1. Para ensaios de imobilização, os filtrados obtidos foram liofilizados. Após a imobilização, foram quantificados os valores de atividade hidrolítica, calculando-se o rendimento de imobilização.

O derivado imobilizado forneceu atividade hidrolítica de $270,7 \pm 30,6 \mathrm{U} / \mathrm{g}$, e rendimento de imobilização de $70 \%$. A argila montmorilonita, também conhecida como esmectita, é um argilomineral que possui camadas compostas por duas folhas tetraédricas de sílica e uma folha central octaédrica de alumina, as quais são unidas por átomos de oxigênio (PAIVA et al., 2008). As camadas desta argila ficam empilhadas e o espaço formado entre elas é denominado galeria, onde há $80 \%$ dos cátions trocáveis (PAIVA et al., 2008). As argilas do tipo montmorilonitas são suportes versáteis e vem sendo muito utilizados para a imobilização de enzimas, por ser uma argila expansível e, desta forma, ter afinidade para adsorção de proteínas. Em adição, seus cátions interlamelares podem ser substituídos por prótons $\left(\mathrm{H}^{+}\right)$e as regiões ácidas do composto também podem atuar como sítios de ligações do grupo amino dos biocatalisadores. 
Assim, as enzimas podem ser adsorvidas tanto na superfície interna quanto externa das camadas desta argila (SUDBRACK, 2012).

Tabela 1 - Dados de biomassa, $\mathrm{pH}$, concentração de proteínas, atividade hidrolítica obtidos para o cultivo do fungo Aspergillus japonicus empregando-se azeite de oliva como substrato

\begin{tabular}{ccccc}
\hline & $\begin{array}{c}\text { Biomassa } \\
(\mathbf{g} / \mathbf{L})\end{array}$ & $\begin{array}{c}\text { Concentração } \\
\text { proteica }(\boldsymbol{\mu g} / \mathbf{m l}) *\end{array}$ & $\begin{array}{c}\text { Atividade } \\
\text { hidrolítica }(\mathbf{U} / \mathbf{m L}) *\end{array}$ & $\begin{array}{c}\text { Atividade } \\
\text { hidrolítica } \\
(\mathbf{U} / \mathbf{g}) * *\end{array}$ \\
\hline \multirow{3}{*}{ Azeite } & 13,96 & $23,75 \pm 1,18$ & $16,928 \pm 0$ & $239,508 \pm 43,76$ \\
\cline { 2 - 5 } & 12,67 & $21,63 \pm 0,92$ & $16,399 \pm 0,75$ & $301,988 \pm 0,42$ \\
\cline { 2 - 5 } & 19,82 & $22,86 \pm 0,27$ & $20,631 \pm 0,75$ & $270,7 \pm 30,60$ \\
\cline { 2 - 6 } & 16,12 & $21,58 \pm 0,50$ & $22,218 \pm 1,49$ & $341,106 \pm 19,81$ \\
\hline MÉDIA & 13,41 & $20,38 \pm 0,47$ & $25,921 \pm 0,75$ & $232,654 \pm 28,61$ \\
\hline
\end{tabular}

\footnotetext{
* média \pm desvio padrão

** lipase imobilizada
}

\subsection{Determinação de pH Ótimo e Temperatura Ótima}

Em trabalho previamente realizado (FERRARI et al., 2016) os valores ótimos de $\mathrm{pH}$ e temperatura determinados para a lipase de $A$. japonicus foram respectivamente $8 \mathrm{e}$ $30^{\circ} \mathrm{C}$. Na figura 1 apresenta-se o perfil de atividade hidrolítica da lipase de A. japonicus imobilizada, em função do $\mathrm{pH}$.

Figura 1 - Determinação do pH ótimo da lipase de Aspergillus japonicus na forma imobilizada

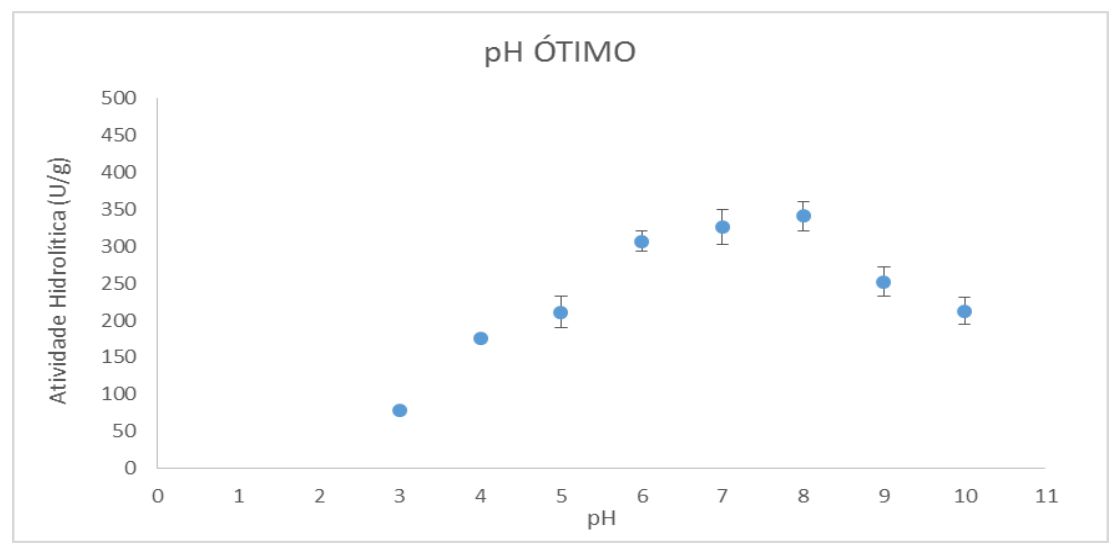

A enzima imobiliza forneceu valor ótimo de pH em 8,0, ou seja, em comparação com a enzima livre, o valor permaneceu o mesmo, e a imobilização parece não ter influenciado no deslocamento do pH. De acordo com Souza et al. (2014), em trabalho realizado com cepas de Aspergillus japonicus, as lipases produzidas por esse microrganismo apresentaram maior atividade em valores de $\mathrm{pH}$ mais alcalinos, fornecendo um $\mathrm{pH}$ ótimo de 8,5. 
Na Figura 2 apresenta-se o perfil de atividade hidrolítica da lipase de $A$. japonicus imobilizada, em função da temperatura. As temperaturas ótimas para lipase de A. japonicus, tanto na forma livre quanto na forma imobilizada foi de $30^{\circ} \mathrm{C}$.

Figura 2 - Determinação da temperatura ótima da lipase de Aspergillus japonicus na forma imobilizada

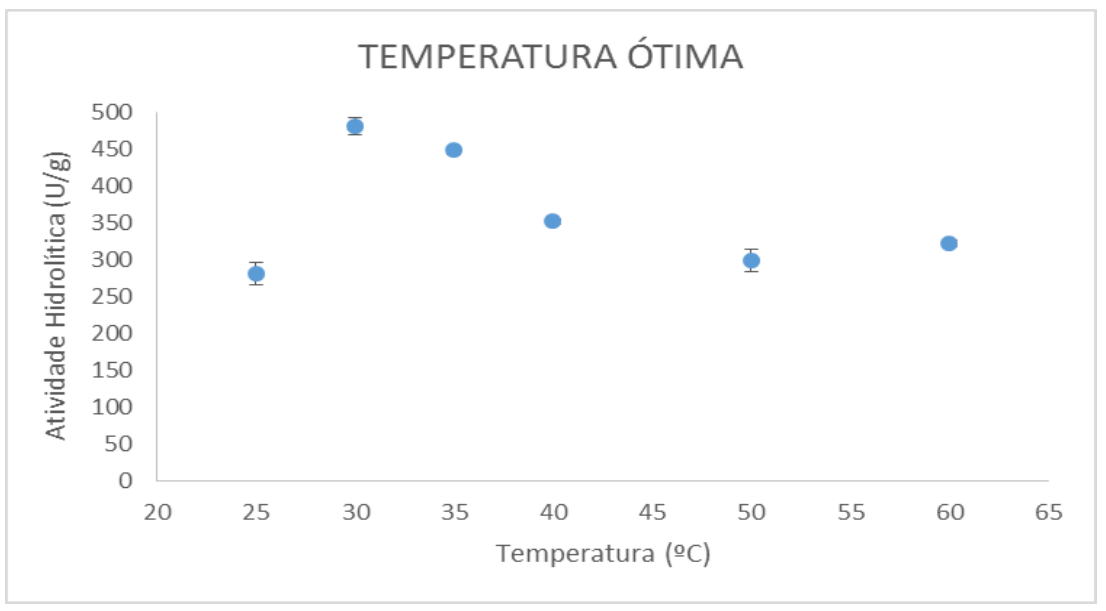

Segundo Colla et al. (2015), em estudo realizado com lipases produzidas a partir de fungos do gênero Aspergillus, a faixa em que a lipase apresenta temperatura ótima dá-se em torno de $37^{\circ} \mathrm{C}$. Analisando-se o perfil da Figura 2, nota-se que a lipase de $A$. japonicus na forma imobilizada aprresentou boa maior estabilidade frente à variação de temperaura. $\mathrm{O}$ resultado apresentado pode sugerir que o processo de imobilização proporcionou uma aumento na faixa de temperatura em que a lipase pode atuar.

\section{CONCLUSÕES}

A Argila Montmorilonita KSF empregada como suporte de imobilização da lipase de Aspergillus japonicus, parece ter sido adequado, permitindo a obtenção de rendimentos de imobilização de $70 \%$, e um biocatalisador com pouca variação nos valores ótimos de $\mathrm{pH}$ e temperatura, em relação à sua forma livre.

\section{AGRADECIMENTOS}

Os autores agradecem à Fundação de Amparo à Pesquisa do Estado de São Paulo (FAPESP-Processo 2016/24564-6).

\section{REFERÊNCIAS}

BRADFORD, M. Analytical Biochemistry. 72, 248-254, 1976.

COLLA, L.M.; FICANHA, A.M.M.; RIZZARDI, J.; BERTOLIN, T.E.; REINEHR, C.O.; COSTA, J.A.V. Production and characterization of lipases by to new isolates of Aspergillus through solid-state and submerged fermentation. BioMed Research International, v. 2015, article ID 725959, 9 pages. 2015. 
CONTESINI, J. F.; LOPES, B. D.; MACEDO. A, G.; NASCIMENTO, G. M.; CARVALHO, O. P. Aspergillus sp. lipase: Potencial biocatalyst for industrial use. Journal of Molecular Catalysis B: Enzymatic, v. 67, p. 163 - 171, 2010.

FERRARI, B. R.; PAULA, A. V.; EBINUMA, V. C. S. Potencial lipolítico do fungo filamentoso Aspergillus japonicus: caracterização e imobilização da lipase. Processo FAPESP 2015/24564-6. Universidade Estadual Paulista "Júlio de Mesquita Filho", Araraquara, 2016.

FERREIRA-DIAS, S.; SANDOVAL, G.; PLOU, F.; VALERO, F. The potential use of lipases in the production of fatty acid derivatives for the food and nutraceutical industries. Eletronic Journal of Biotechnology, v. 17, n 3, p. 1-38, 2013.

GUISAN, J. M. "Immobilization of enzymes and cells". 2nd ed., Institute of Catalysis, CSIC Campus UAM-Cantoblanco- Madrid, Spain, 2006.

HASAN, F.; SHAH, A. A.; HAMEED, A. Methods for detection and characterization of lipases: A comprehensive review. Biotechnology Advances, v. 27, n 6, p. 782-798, 2009.

MHETRAS, N.C.; PATIL, S.; GOKHALE, D. Lipase of Aspergillus niger NCIM 1207: A Potential Biocatalyst for Synthesis of Isoamyl Acetate. Indian Journal of Microbiology, v. 50, p. 432, 2010.

NUNES, P.A.; PIRES-CABRAL, P.; FERREIRA-DIAS, S. Production of olive oil enriched with medium chain fatty acids catalysed by commercial immobilised lipases. Food Chemistry, v. 127, p. 993-998, 2011.

PADILHA, G.S.; FERREIRA, J.F.; CASTIGLIONI G.L.; ALEGRE, R.M.; TAMBOURGI, E.B. Avaliação da lipase extracelular de Pseudomonas cepacia para purificação em sistema bifásico aquoso. Ciência Tecnologia de Alimentos, v.31, n.1, p. 16-22, 2011.

PAULA, A. V. Reestruturação da gordura de leite por interesterificação enzimática empregando lipase imobilizada: otimização das condições reacionais e operacionais. 2011. 212 p. Tese (Doutorado em Ciências) - Escola de Engenharia de Lorena, Universidade de São Paulo, Lorena/SP, 2012.

SUDBRACK, T.S. Imobilização de lipase em montmorilonita e aplicação em reações oleoquímicas. 2012. 66f. Dissertação (Mestrado em Química) - Instituto de Química, Universidade Federal do Rio Grande do Sul, Porto Alegre/RS, 2012.

VESCOVI, V.; KOPP, W.; GUISÁN, J. M.; GIORDANO, R. L. C.; MENDES, A. A.; TARDIOLI, P. W. Improved catalytic properties of Candida antarctica lipase Bmultiattached on tailor-made hydrophobic silica containing octyland multifunctional aminoglutaraldehyde spacer arms. Process Biochemistry. 2016. 